\title{
COVID-19-Associated Myelitis Involving the Dorsal and Lateral White Matter Tracts: A Case Series and Review of the Literature
}

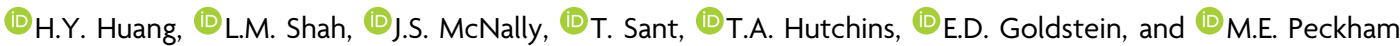

\section{ABSTRACT}

SUMMARY: Coronavirus disease 2019 (COVID-19) myelitis is a rare condition, most commonly presenting with nonenhancing central expansile cord T2 signal changes. A single case report has also described longitudinal involvement of the dorsal columns. We present 5 cases of COVID-19-associated myelitis with tract-specific involvement of the dorsal and lateral columns and discuss potential pathophysiologic pathways for this unique pattern.

ABBREVIATION: COVID-19 = coronavirus disease 2019

C oronavirus disease 2019 (COVID-19) is primarily known as a respiratory illness; however, neurologic responses to this infection have been increasingly described, including infectious encephalopathy, meningoencephalitis, Guillain-Barre syndrome, and stroke. ${ }^{1}$ Myelitis has been reported multiple times as a postinfectious inflammatory reaction from COVID-19 infection. Previously documented cases have predominantly described central longitudinal T2 changes without corresponding enhancement, ${ }^{2-12}$ with 2 cases of autoimmune myelitis (antimyelin oligodendrocyte glycoprotein-spectrum disorder and aquaporin4 neuromyelitis optica) also found to be associated with COVID19 infection. ${ }^{13,14}$ At the more extreme ends of the spectrum, 1 report described T2-bright and centrally necrotic enhancing lesions, ${ }^{15}$ with another case presenting with clinical symptoms of transverse myelitis with paraplegia below the T10 level but with a normal appearance of the spinal cord on clinical MR imaging. ${ }^{16}$ A few cases have noted more tract-specific disease, with 1 case demonstrating ventral horn-predominant T2 hyperintensity and acute flaccid myelitis ${ }^{17}$ and 1 interesting case demonstrating dorsal column-predominant T2 signal abnormality with progressive numbness in the feet and hands. ${ }^{18}$

Received May 11, 2021; accepted after revision June 30

From the Departments of Neurology (H.Y.H., E.D.G.) and Radiology and Imaging Sciences (L.M.S., J.S.M., T.A.H., M.E.P.), and School of Medicine (T.S.), University of Utah, Salt Lake City, Utah.

Please address correspondence to Miriam E. Peckham, MD, Department of Radiology and Imaging Sciences, University of Utah Health Sciences Center, 30 North, 1900 East, 1A071, Salt Lake City, UT 84132-2140; e-mail:

Miriam.Peckham@hsc.utah.edu; @Miriam_Peckham

-- Indicates open access to non-subscribers at www.ajnr.org

Indicates article with online supplemental data.

http://dx.doi.org/10.3174/ajnr.A7256
Although most reports of COVID-19-associated myelitis have noted central-predominant $\mathrm{T} 2$ signal change, we describe 5 cases demonstrating lateral and dorsal column-specific disease. All patients were seen at our single academic institution, and were the only 5 cases of COVID-19-associated myelitis diagnosed and treated since the beginning of the pandemic in March 2020.

Case 1

Presentation. A 62-year-old woman without prior neurologic disease presented 10 days after a COVID-19 diagnosis with a 1 -day history of rapidly ascending numbness with gait impairment and fecal incontinence. She previously experienced mild COVID-19 symptoms, including anosmia and cough, which had resolved several days before her hospitalization. Her examination findings were notable for diffuse hyperreflexia and reduced vibratory and pinprick sensations distally with sensory ataxia.

Laboratory Findings. Serum laboratory evaluation demonstrated elevated inflammatory markers including erythrocyte sedimentation rate and C-reactive protein, a ganglioside panel positive for ganglioside-monosialic acid antibodies, and CSF with elevated lymphocytes. CSF protein and glucose levels were normal. Further laboratory studies were unremarkable, including vitamins B3, B6, B12, copper, methylmalonic acid, vitamin E, and viral panels (Online Supplemental Data).

Imaging Findings. Thoracic spine MR imaging showed patchy areas of T2 hyperintensity as well as patchy areas of enhancement throughout the thoracic cord, predominantly involving the lateral cord and dorsal columns (Fig 1). There was also ventral and 


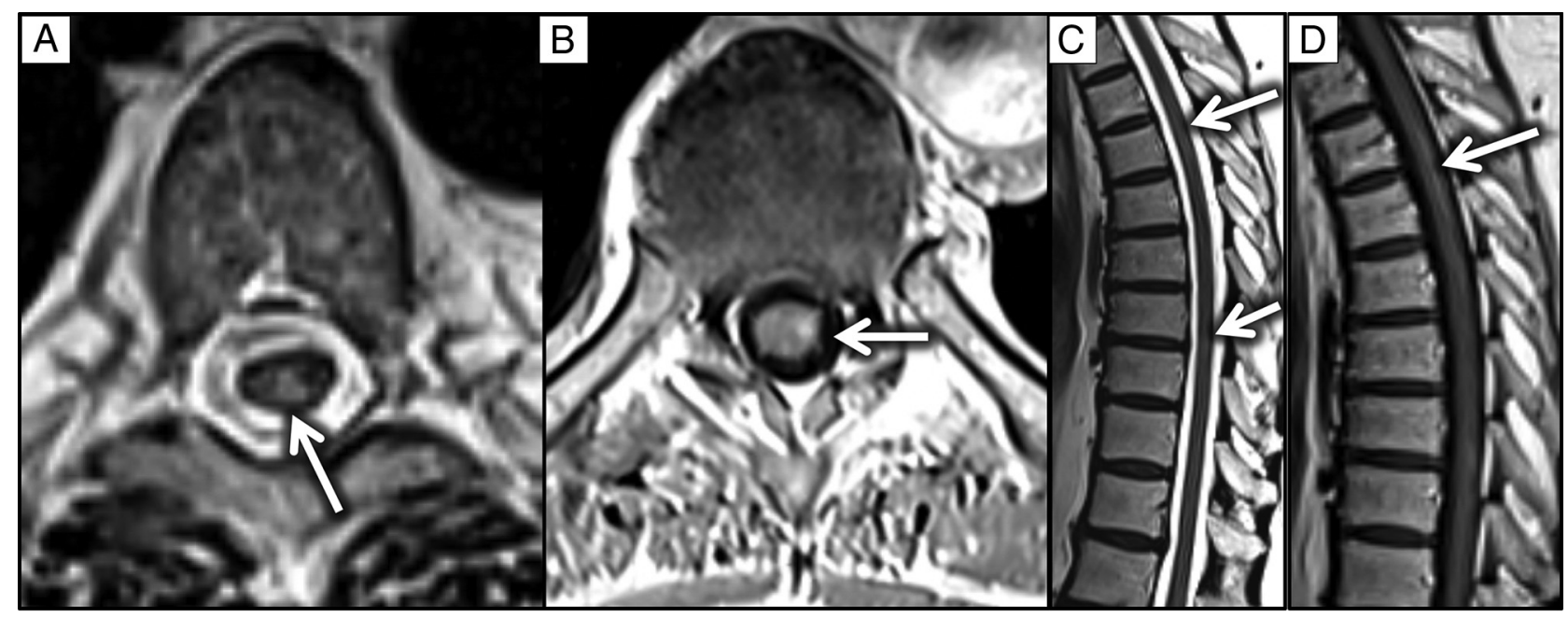

FIG 1. Axial T2 $(A)$, and T1 postcontrast $(B)$ images demonstrate $T 2$ hyperintensity involving the posterior columns and patchy enhancement predominantly in the posterior and lateral columns (arrow pointing to posterior column in $A$, and arrow to lateral column in $B$ ). Sagittal T2 (C) and postcontrast $\mathrm{Tl}(D)$ images demonstrate corresponding signal changes (arrows).

dorsal nerve root enhancement along the cauda equina. MR imaging findings of the brain were unremarkable, with no enhancing lesions or other pathology. Electromyography and nerve conduction studies were obtained 12 days after the onset of symptoms, which did not show electrodiagnostic evidence of a peripheral polyneuropathy.

Management. Treatment with plasma exchange and oral prednisone was initiated with improvement in her clinical symptoms. She was discharged with a month-long oral prednisone taper. At the 4-month follow-up visit, her previous clinical symptoms had largely resolved.

\section{Case 2}

Presentation. A 79-year-old man with a history of hypertension, hyperlipidemia, prior back surgery, and chronic low back pain requiring a walker for ambulation at baseline presented with a 2month history of worsening lower extremity weakness and fecal incontinence. He had been diagnosed with COVID-19 infection approximately 2 weeks before symptom onset. His examination was notable for paraparesis with minimal right-ankle dorsiflexion and plantar flexion, areflexia, and increased tone in his lower extremities, as well as reduced vibration and proprioception in a length-dependent pattern.

Laboratory Findings. Serum laboratory evaluation demonstrated elevated inflammatory markers (erythrocyte sedimentation rate and C-reactive protein), but CSF studies showed a normal white blood cell count and protein and glucose levels. Further laboratory studies showed normal vitamins B1, B12, vitamin E, folate, copper, monoclonal protein, and methylmalonic acid levels. He was found to be heterozygous for the methylenetetrahydrofolate reductase (MTHFR) genes (C665T and A1286C) (Online Supplemental Data).

Imaging Findings. MR imaging demonstrated ventral medullary and left-lateral/dorsal-lateral cord signal abnormality from C2 through C3 along with patchy lateral and dorsal column involvement of the mid and lower cervical cord and thoracic cord with associated diffusion restriction (Fig 2). There was no associated enhancement. Electromyography and nerve conduction studies showed signs of active denervation in the proximal-greater-thandistal lower extremities.

Management. He was treated with 5 days of intravenous immunoglobulin and 5 sessions of plasma exchange, unfortunately without notable improvement in symptoms. He was then discharged to inpatient rehabilitation with a rehabilitation course complicated by urinary tract infection and aspiration pneumonitis. After extensive inpatient rehabilitation, he demonstrated improvement in his functional status and was discharged home.

\section{Case 3}

Presentation. A 40-year-old woman with a medical history including kidney transplant secondary to focal segmental glomerulosclerosis on chronic immunosuppression, latent tuberculosis, and diabetes mellitus type 2 presented with new and rapid onset of low back pain, lower extremity weakness, and sensory changes. She developed these symptoms within a few days of testing positive for COVID-19. Her examination findings were notable for hyperreflexia in the lower extremities and decreased strength in the proximal-greater-than-distal lower extremities with preserved sensation.

Laboratory Findings. Serum laboratory evaluation demonstrated an elevated inflammatory marker (erythrocyte sedimentation rate with normal C-reactive protein levels). CSF studies showed a normal white blood cell count and protein and glucose levels, but 11 unique oligoclonal bands. Findings for evaluation of serum antibodies including myelin oligodendrocyte glycoprotein aquaporin-4 antibody immunoglobulin G for demyelinating disease were negative. Other laboratory studies included normal vitamin B12, B1, B6, D, copper, and folate levels (Online Supplemental Data). In the setting of her immunosuppressive 


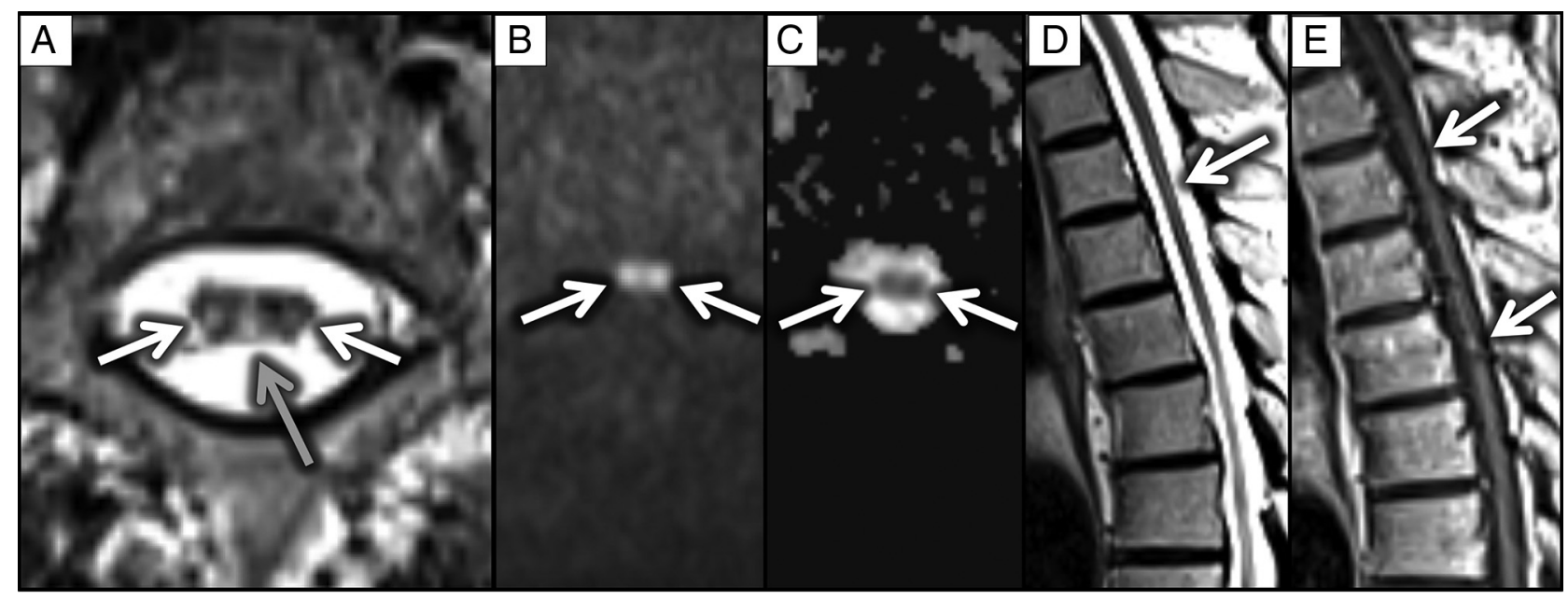

FIG 2. Axial T2 $(A)$ and diffusion-weighted $(B)$ images demonstrate T2 hyperintensity involving the posterior (gray arrow) and lateral columns (white arrows) with corresponding DWI hyperintensity and ADC hypointensity $(C)$ confirming restriction (white arrows). Findings were less conspicuous on sagittal T2 (D) and postcontrast T1 (E) images, with only faint signal changes present (white arrows).

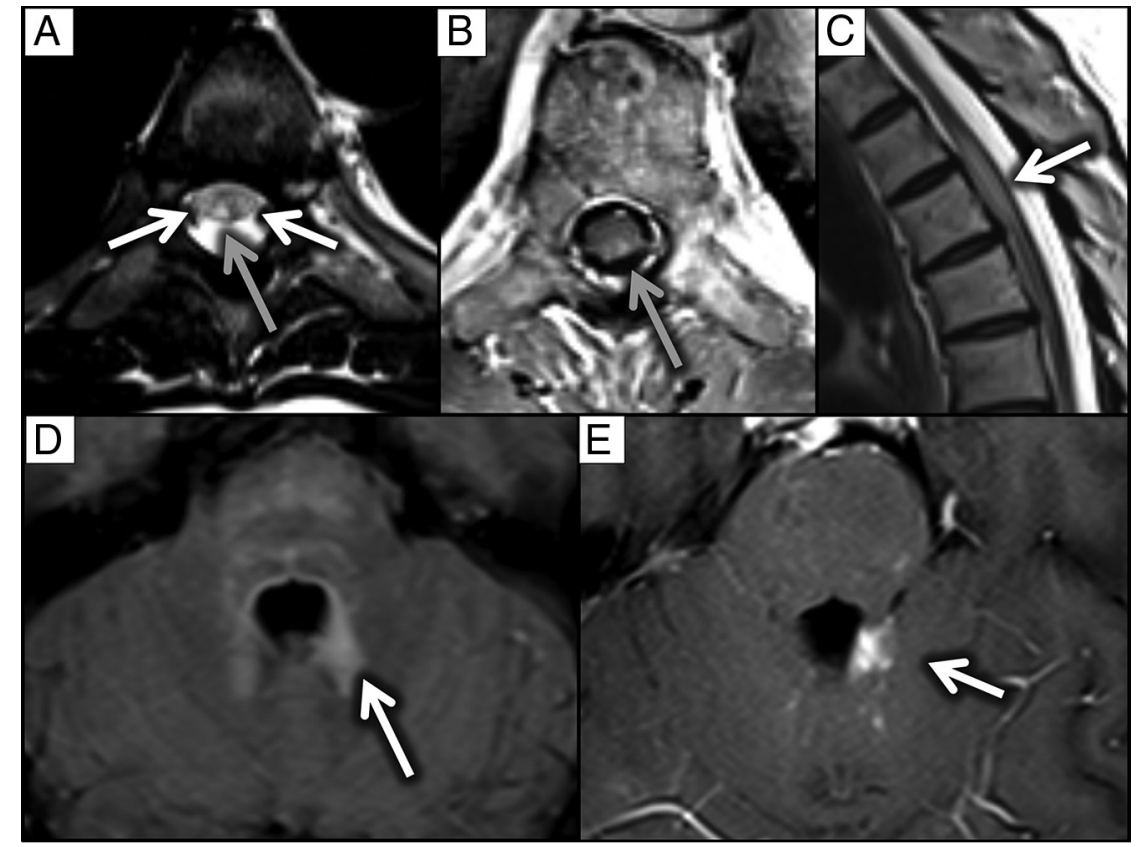

FIG 3. Axial $T 2(A)$ and $T 1$ postcontrast $(B)$ images demonstrate $T 2$ hyperintensity involving the posterior columns (gray arrow), with faint involvement of the lateral columns (white arrows, $A$ ). There was corresponding scattered patchy enhancement in these regions (gray arrow, B). T2 hyperintensity and expansion of the upper thoracic cord was well-demonstrated on sagittal views (white arrow, C). Brain MR imaging shows T2/FLAIR hyperintensity and corresponding enhancement surrounding the fourth ventricle (white arrows, $D$ and $E$ ).

state, extensive infectious work-up was performed, which did not show evidence of active infection. Electromyography and nerve conduction studies showed no evidence of neuropathy or myopathy.

Imaging Findings. MR imaging of the brain showed T2 and FLAIR hyperintensities with enhancement in the midbrain, pons, and medulla. MR imaging of the spine showed multifocal T2/
STIR hyperintensities and enhancement predominantly involving the dorsal and lateral columns within the cervical and thoracic spinal cord (Fig 3). Intracranial MR vessel wall imaging showed no arterial narrowing or abnormal enhancement along the vessel walls.

Management. She was given a 3day course of high-dose intravenous methylprednisolone with subjective improvement in her symptoms. She was discharged home with an increased dose of oral prednisone along with her other immunosuppressive medications. Unfortunately, during the course of several months, she developed worsening symptoms, including increased weakness, gait instability, severe constipation, and sensory changes. Repeat MR imaging demonstrated worsened T2-hyperintense enhancing lesions at the level of T3-T4 as well as new enhancing brain lesions with enhancement most pronounced in the basal ganglia, pons, and cerebellum. Further investigation regarding other etiologies of her encephalomyelitis, including unremarkable brain biopsy findings, have been unrevealing thus far, and her working diagnosis remains COVID-19-associated encephalomyelitis.

\section{Case 4}

Presentation. A 62-year-old man with a history of end-stage renal disease on hemodialysis, diabetes mellitus type 2, hypertension, and hyperlipidemia presented with back pain, fever, cough, 


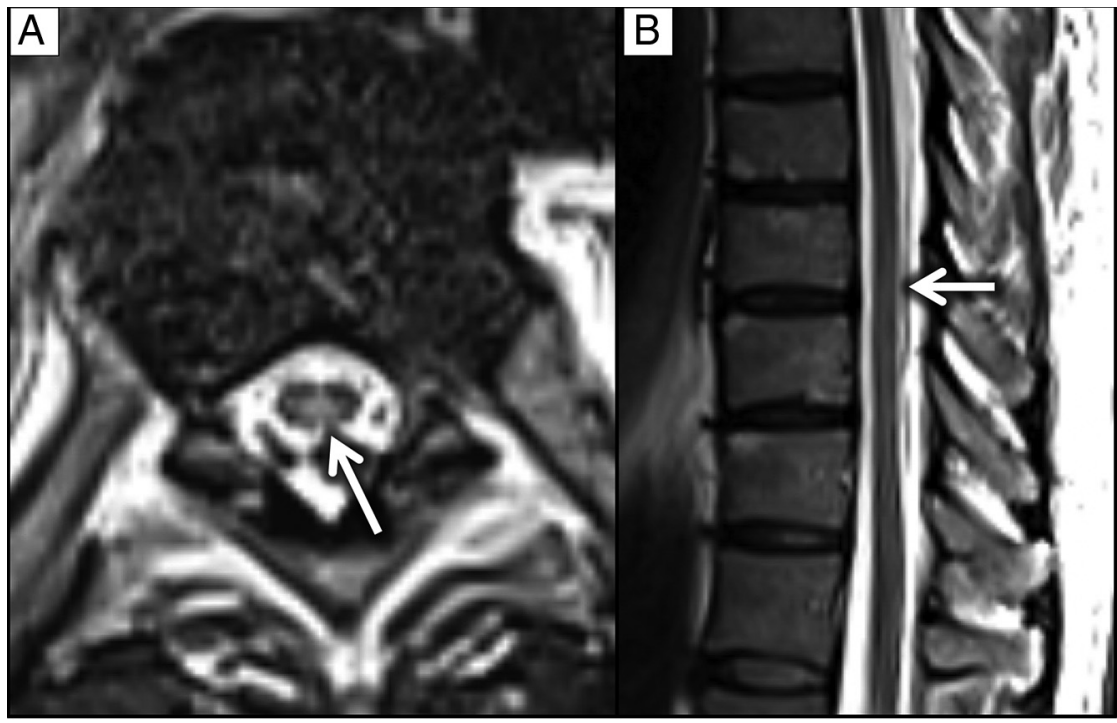

FIG 4. Axial T2 image through the thoracic cord demonstrates $T 2$ hyperintensity involving the posterior columns (white arrow). Subtle hyperintensity could be seen in this region on sagittal T2 images (white arrow).

and chills. Symptoms started 2 days after receiving the COVID19 vaccine, and he subsequently tested positive for COVID-19 infection. His examination was notable for mildly decreased strength in the bilateral upper extremities with intact strength in the lower extremities without noted sensory deficits.

Laboratory Findings. Serum evaluation demonstrated elevated inflammatory markers including erythrocyte sedimentation rate and C-reactive protein. Vitamin B12 and folate levels were normal (Online Supplemental Data).

Imaging Findings. MR imaging of the spine showed intramedullary T2 hyperintensities throughout the cervical and thoracic cord, predominantly involving the lateral and dorsal columns (Fig 4).

Management. He was discharged with medications for pain management, but no immunomodulating therapies were prescribed.

\section{Case 5}

Presentation. A 64-year-old man with no prior neurologic history on zinc supplementation during the COVID-19 pandemic, presented with a 3-month history of lower extremity paresthesia and gait imbalance, which had a rapid onset 2 days after diagnosis of COVID-19 infection. Physical examination findings were notable for lower extremity hyperreflexia and reduced vibratory and proprioceptive sensations in a length-dependent pattern with sensory ataxia and preservation of strength.

Laboratory Findings. Serum laboratory evaluation demonstrated an elevated zinc level and an undetectable copper level (Online Supplemental Data).

Imaging Findings. Findings of MR imaging of the brain were unremarkable, with no enhancing lesions or other pathology. MR imaging of the spine showed diffuse T2-hyperintense signal abnormality predominantly involving the dorsal columns throughout the length of the spinal cord (Fig 5). Electromyography and nerve conduction studies demonstrated mild axonal neuropathy.

Management. He underwent oral copper supplementation. On repeat evaluation 3 months later, he reported no subjective improvement in his symptoms. Testing for serum copper levels was repeated at that time with findings within normal limits.

\section{DISCUSSION}

Hypothesized mechanisms for neurologic sequelae of COVID-19 have been ascribed to a systemic inflammatory response or sequela of critical illness. ${ }^{19}$ While multiple reports have described associated nonspecific central cord edema, few have demonstrated tract-specific disease in the setting of this virus. ${ }^{18}$

Lateral and dorsal column involvement is relatively atypical in viral myelitis, which usually demonstrates a propensity for central gray matter regions of the cord. ${ }^{20}$ While infectious posterior column involvement has been seen in HIV, ${ }^{21}$ and posterior and lateral column involvement in human T-cell lymphotropic virus type 1 -associated myelopathy, ${ }^{22}$ involvement of these regions is more commonly seen in the noninfectious setting of subacute combined degeneration. ${ }^{20}$ Subacute combined degeneration is caused by a disturbance in the methylation pathway, ${ }^{23}$ which can stem from metabolic causes such as vitamin $B 12^{24}$ and copper deficiency, vitamin E deficiency, ${ }^{25,26}$ and toxic causes such as excess nitrous oxide (secondarily causes qualitative B12 deficiency), ${ }^{27}$ and intrathecal methotrexate. ${ }^{28}$ Metabolic and nutritional factors have been found to have key roles in supporting the immune system, specifically in the setting of COVID-19, ${ }^{29}$ with some evidence supporting vitamin B12 supplementation in the fight against this pathogen. ${ }^{30}$

It can only be speculated that COVID-19 may affect the methylation cycle, which, in turn, may expose deficiencies in the immune system that are supported by this pathway. This finding may be supported by dorsal and sometimes lateral column involvement in these cases as well as in the 2 cases that demonstrated an underlying propensity for methylation cycle abnormalities. In case 2, the patient was heterozygous for mutation of the MTHFR gene, which has been found to strongly predispose to subacute combined degeneration. ${ }^{31}$ Most interesting, the MTHFR C677T polymorphism has also previously been found to predispose to a more severe course of COVID-19, with vitamin supplementation recommended in individuals with this mutation. ${ }^{32}$ In case 5 , the patient had an underlying copper deficiency, likely resulting from zinc toxicity from supplementation. Although this may be considered a confounder for the patient's myelitis findings, clinical symptoms of rapid onset are in line 


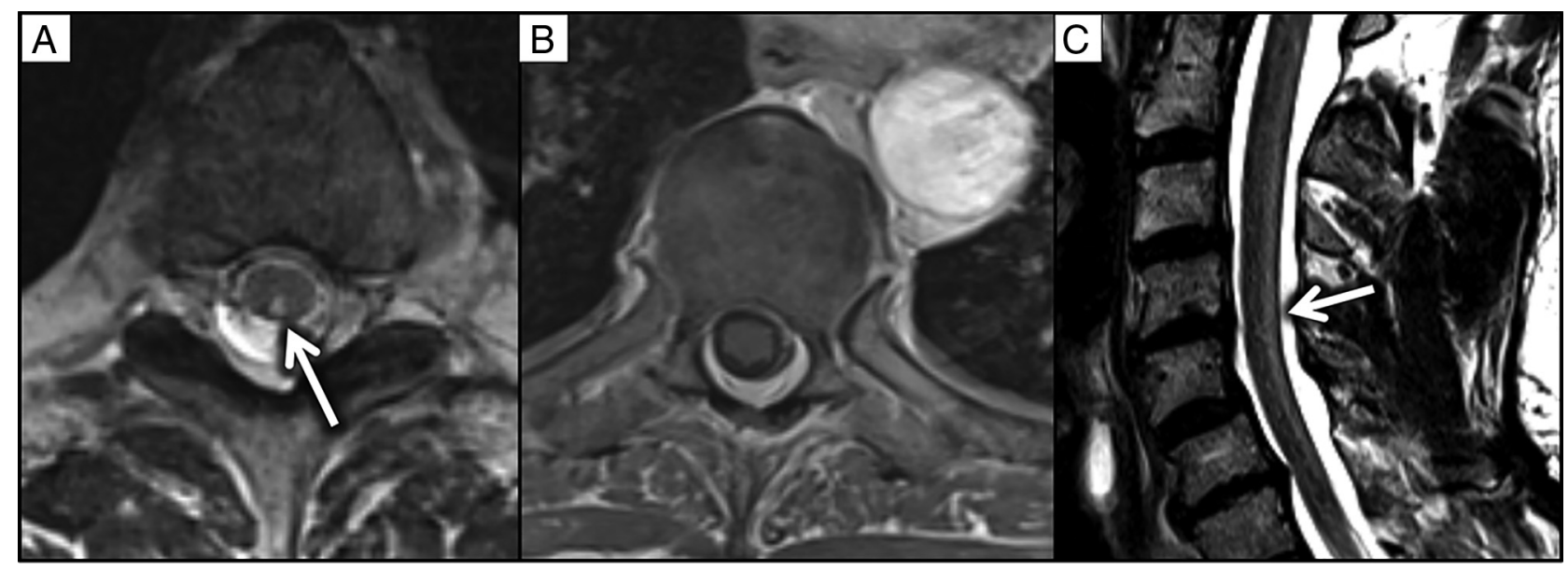

FIG 5. Axial T2 $(A)$ and $\mathrm{T} 1$ postcontrast $(B)$ images through the thoracic cord demonstrate $\mathrm{T} 2$ hyperintensity involving the posterior columns (white arrow), with no corresponding enhancement. A sagittal T2 image in the cervical spine (C) demonstrates hyperintensity along the dorsal aspect of the cord (white arrow).

with the other reported COVID-19-associated cases, and these symptoms did not improve with reversal of the copper deficiency.

Most interesting, none of the 5 COVID-19-associated cases of myelitis diagnosed and treated at our institution demonstrated the predominantly central expansile T2-signal hyperintensity reported most commonly throughout the literature. ${ }^{2-12}$ This finding may be related to regional differences in viral strains or environmental factors. Additionally, it may be that this tract-specific appearance, only rarely described in the literature, is not always clinically attributed to the patient's COVID-19 status.

Work-up and management of these 5 patients varied widely. These differences can be attributed to inpatient-versus-outpatient evaluation as well as different primary services overseeing their care. Ideally, further investigation regarding the mechanism and etiology of COVID-19 myelitis would provide a more comprehensive and consistent evaluation of these patients.

\section{CONCLUSIONS}

Imaging features of dorsal and lateral white matter tract viral/ postviral involvement further support a vitamin deficiency/nutritional component to the severity of COVID-19 symptoms. A link between the pathophysiology of COVID-19 and the methylation pathway is possible.

Disclosure forms provided by the authors are available with the full text and PDF of this article at www.ajnr.org.

\section{REFERENCES}

1. Whittaker A, Anson M, Harky A. Neurological manifestations of COVID-19: a systematic review and current update. Acta Neurol Scand 2020;142:14-22 CrossRef Medline

2. Munz M, Wessendorf S, Koretsis G, et al. Acute transverse myelitis after COVID-19 pneumonia. J Neurol 2020;267:2196-97 CrossRef Medline

3. Chow CC, Magnussen J, Ip J, et al. Acute transverse myelitis in COVID-19 infection. BMJ Case Rep 2020;13:e236720 CrossRef Medline

4. Chakraborty U, Chandra A, Ray AK, et al. COVID-19-associated acute transverse myelitis: a rare entity. BMJ Case Rep 2020;13: e238668 CrossRef Medline
5. Kaur H, Mason JA, Bajracharya M, et al. Transverse myelitis in a child with COVID-19. Pediatr Neurol 2020;112:5-6 CrossRef Medline

6. AlKetbi R, AlNuaimi D, AlMulla M, et al. Acute myelitis as a neurological complication of Covid-19: a case report and MRI findings. Radiol Case Rep 2020;15:1591-95 CrossRef Medline

7. Baghbanian SM, Namazi F. Post COVID-19 longitudinally extensive transverse myelitis (LETM): a case report. Acta Neurol Belg 2020 Sept 18. [Epub ahead of print] CrossRef Medline

8. Fumery T, Baudar C, Ossemann M, et al. Longitudinally extensive transverse myelitis following acute COVID-19 infection. Mult Scler Relat Disord 2021;48:102723 CrossRef Medline

9. Valiuddin H, Skwirsk B, Paz-Arabo P. Acute transverse myelitis associated with SARS-CoV-2: a case-report. Brain Behav Immun Health 2020;5:100091 CrossRef Medline

10. Khedr EM, Karim AA, Soliman RK. Case report: acute spinal cord myelopathy in patients with COVID-19. Front Neurol 2020;11:610648 CrossRef Medline

11. Garg RK, Paliwal VK, Gupta A. Spinal cord involvement in COVID-19: a review. J Spinal Cord Med 2021 Mar 11. [Epub ahead of print] CrossRef Medline

12. Rodríguez de Antonio LA, González-Suárez I, Fernández-Barriuso I, et al. Para-infectious anti-GD2/GD3 IgM myelitis during the Covid-19 pandemic: case report and literature review. Mult Scler Relat Disord 2021;49:102783 CrossRef Medline

13. Zhou S, Jones-Lopez EC, Soneji DJ, et al. Myelin oligodendrocyte glycoprotein antibody-associated optic neuritis and myelitis in COVID-19. J Neuroophthalmol 2020;40:398-402 CrossRef Medline

14. Shaw VC, Chander G, Puttanna A. Neuromyelitis optica spectrum disorder secondary to COVID-19. Br J Hosp Med (Lond) 2020;81:13 CrossRef Medline

15. Sotoca J, Rodríguez-Álvarez Y. COVID-19-associated acute necrotizing myelitis. Neurol Neuroimmunol Neuroinflamm 2020;7:e803 CrossRef Medline

16. Zachariadis A, Tulbu A, Strambo D, et al. Transverse myelitis related to COVID-19 infection. J Neurol 2020;267:3459-61 CrossRef Medline

17. Abdelhady M, Elsotouhy A, Vattoth S. Acute flaccid myelitis in COVID-19. BJR Case Rep 2020;6:20200098 CrossRef Medline

18. Kim JW, Abdullayev N, Neuneier J, et al. Post-COVID-19 encephalomyelitis. Neurol Res Pract 2021;3:18 CrossRef Medline

19. Ellul MA, Benjamin L, Singh B, et al. Neurological associations of COVID-19. Lancet Neurol 2020;19:767-83 CrossRef Medline 
20. Kranz PG, Amrhein TJ. Imaging approach to myelopathy: acute, subacute, and chronic. Radiol Clin North Am 2019;57:257-79 CrossRef Medline

21. Di Rocco A. Diseases of the spinal cord in human immunodeficiency virus infection. Semin Neurol 1999;19:151-55 CrossRef Medline

22. Umehara F, Nose H, Saito M, et al. Abnormalities of spinal magnetic resonance images implicate clinical variability in human $\mathrm{T}$ cell lymphotropic virus type I-associated myelopathy. J Neurovirol 2007;13:260-67 CrossRef Medline

23. Winston GP, Jaiser SR. Copper deficiency myelopathy and subacute combined degeneration of the cord: why is the phenotype so similar? Med Hypotheses 2008;71:229-36 CrossRef Medline

24. Cao J, Su ZY, Xu SB, et al. Subacute combined degeneration: a retrospective study of 68 cases with short-term follow-up. Eur Neurol 2018;79:247-55 CrossRef Medline

25. Kumar N, Gross JB Jr, Ahlskog JE. Copper deficiency myelopathy produces a clinical picture like subacute combined degeneration. Neurology 2004;63:33-39 CrossRef Medline

26. Rowin J, Lewis SL. Copper deficiency myeloneuropathy and pancytopenia secondary to overuse of zinc supplementation. J Neurol Neurosurg Psychiatry 2005;76:750-51 CrossRef Medline
27. Pema PJ, Horak HA, Wyatt RH. Myelopathy caused by nitrous oxide toxicity. AJNR Am J Neuroradiol 1998;19:894-96 Medline

28. Yi Y, Kang HJ, Shin HY, et al. Progressive myelopathy mimicking subacute combined degeneration after intrathecal chemotherapy. $J$ Child Neurol 2015;30:246-49 CrossRef Medline

29. Calder PC. Nutrition, immunity and COVID-19. BMJ Nutr Prev Health 2020;3:74-92 CrossRef Medline

30. Wee AK. COVID-19's toll on the elderly and those with diabetes mellitus: is vitamin B12 deficiency an accomplice? Med Hypotheses 2021;146:110374 CrossRef Medline

31. Zhang X, Hou C, Liu P, et al. Methylenetetrahydrofolate reductase (MTHFR) C677T polymorphism and subacute combined degeneration: revealing a genetic predisposition. Front Neurol 2018;9:1162 CrossRef Medline

32. Karst M, Hollenhorst J, Achenbach J. Life-threatening course in coronavirus disease 2019 (COVID-19): is there a link to methylenetetrahydrofolic acid reductase (MTHFR) polymorphism and hyperhomocysteinemia? Med Hypotheses 2020;144:110234 CrossRef Medline 